\title{
Interactive comment on "Physically based summer temperature reconstruction from ice layers in ice cores" by Koji Fujita et al.
}

\section{Koji Fujita et al.}

cozy@nagoya-u.jp

Received and published: 28 November 2019

\section{Dear Reviewer \#3}

Thank you for your comments on our manuscript submitted to CP.

[reviewer comment] General Comments: This manuscript presents a new way to reconstruct past temperature from ice cores. Encouragingly, this method relies on the melt features that can frequently confound the estimation of temperature using more traditional methods of variations in oxygen (and potentially hydrogen) isotopes. The manuscript tests the method on a range of ice cores which are widely differentiated both geographically and in elevation. The data encapsulated in Figure 8 indeed looks very encouraging. 
[author reply] Thanks for the positive evaluation.

[reviewer comment] Line 31-32 - are there any more recent references to melt features being used to characterise temperature? Apart from a couple in the 2000's, these references are 20 or more years old.

[author reply] We have checked papers including keywords ["ice core" and "temperature" and "reconstruction"] in Google Scholar for the period 2011-2019 (results $\sim 17,200$ ). Among the first 150 papers sorted by relevance (after these, conference abstracts increase), we exclude studies using tree ring or sediment core. And we found that 85 papers use isotopic approach (including papers using existing data), seven papers use borehole temperature, one paper deals with gas analysis, four papers use other proxies (pollen, bubble and ELA), and TWO papers adopt ice-layer approach. Furthermore, one of the two papers is our study (Okamoto et al., 2011, JGR) which has been already cited in this study. So, we could find only one study in Antarctic Peninsula by Abram et al. (2013, Nature Geosci.). We will add this study to our revised manuscript.

[reviewer comment] Are you talking about melt layers in the ice? Layer thickness in ice cores usually refers to annual layer thickness.

[author reply] We changed the term to "melt layers" including the title.

[reviewer comment] Where are your methods where you outline the analysis of the ice cores you used, and thus how they were dated. The annual layer dating of these cores is critical to this project since you are trying to reconstruct summer mean temperature.

[author reply] Although it is difficult to understand what the first sentence intends to mean, we imagine that you request more details of the ice cores and their dating method. Dating methods are different ice-core by ice-core, which are described in publications listed in Table 1. We will add brief descriptions and add information to Table 1 (dating method and error).

Printer-friendly version

Discussion paper 
[reviewer comment] Was there a reason to not use ERA5 rather than ERA interim? ERA 5 would provide a smaller grid size, and therefore parameters like $2 \mathrm{~m}$ temp may be more realistic. ERA 5 is likely far more relevant to a study looking at calibrating grid data with specific ice core sites.

[author reply] This is because we have easy access to the ERA-Interim data (already downloaded and modified to daily data). In addition, there is no way to confirm which dataset (including NCEPs, MERRA and others) is "realistic" at ice core sites where observational data is generally unavailable. Validity of ERA-Interim air temperature has been tested with several observational data in the high mountain Asia (Sakai et al., 2015) though they are not located at high-elevation ice core site but around glacier termini. However, representativeness of those dataset does not matter in this study because air temperature and precipitation are systematically modified to obtain "lookup table". Our sensitivity tests show that the annual temperature range only affects the estimated SMT. This suggests that the reanalysis data would be suitable for demonstrating this study if the annual temperature range was reliable at the ice core sites even though the representativeness of temperature and precipitation amount were not precise. We will add some descriptions about this in the revised manuscript. Other effective parameters are precipitation and firn albedo. But precipitation is a given parameter from ice core and issue of firn albedo (and albedo scheme improvement) is already addressed in the original manuscript.

[reviewer comment] How were the 'ice layers' or melt layers differentiated from bubble free layers that may have formed via other means? E.g. bubble free layers in ice cores have been observed at various sites and have been differentiated from melt layers via their appearance (Feyveresi et al., 2018, The Cryosphere 12:325-341) and even via analysis of their noble gas chemistry (Orsi et al., 2015, J. Glaciology doi:10.3189/2015JoG14J237). These layers can result from surface crusts that have been retained and buried, and the surface crusts may have formed via wind scouring, or other atmospheric processes like inversions. These are not melt processes.

Interactive comment
Printer-friendly version

Discussion paper

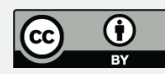


The study needs to provide some detail of how melt layers were discerned from other layers in the cores - perhaps including some photos?

[author reply] Because this study does not aim to develop a method identifying melt layer, we have no idea about this comment. We will add some descriptions addressing that those "melt-layer-like" layers would affect the estimated SMT but those layers would be thinner than melt layer.

Interactive

comment

[reviewer comment] Specific Comments: I suggest some proof-reading to improve the English. There are numerous instances of missing words, e.g. first sentence of the abstract "...relied on the statistical analysis...", line 29 'because the relationship....

[author reply] Though the original manuscript has been checked by an English editing service, we will ask it again with this caution.

[reviewer comment] What does 'firn albedo setting' mean in the abstract? Perhaps explain briefly here.

[author reply] We changed here as "firn albedo, which is a fixed value in the model,".

[reviewer comment] It would be useful to provide some more detail about the nearby stations used in Table one - e.g. elevation, length of observations, not only distance but also direction from the ice core site.

[author reply] We provide the information of meteorological stations; location (Lon., Lat., elevation), starting year of observation, and direction from the corresponding ice core site as a supplementary table.

[reviewer comment] Can you split the data in figure 8 into four separate graphs on the one figure? It would be preferable to see the four sites more clearly. Another option would simply be to make the $\mathrm{x}$ axis far longer (although still covering the same temp interval) so that it is easier to differentiate the four sites. It is hard to see the orange and pink dots.

Printer-friendly version

Discussion paper 
[author reply] In this figure, we want to show different relationships between ice layer thickness and reconstructed SMT so that separated graphs is not our preference. We CPD made the $x$-axis 1.5 times longer than the present one and smaller the symbols to show red dots behind blue dots (shown as Fig. 1).

Interactive comment on Clim. Past Discuss., https://doi.org/10.5194/cp-2019-97, 2019.

Interactive comment 


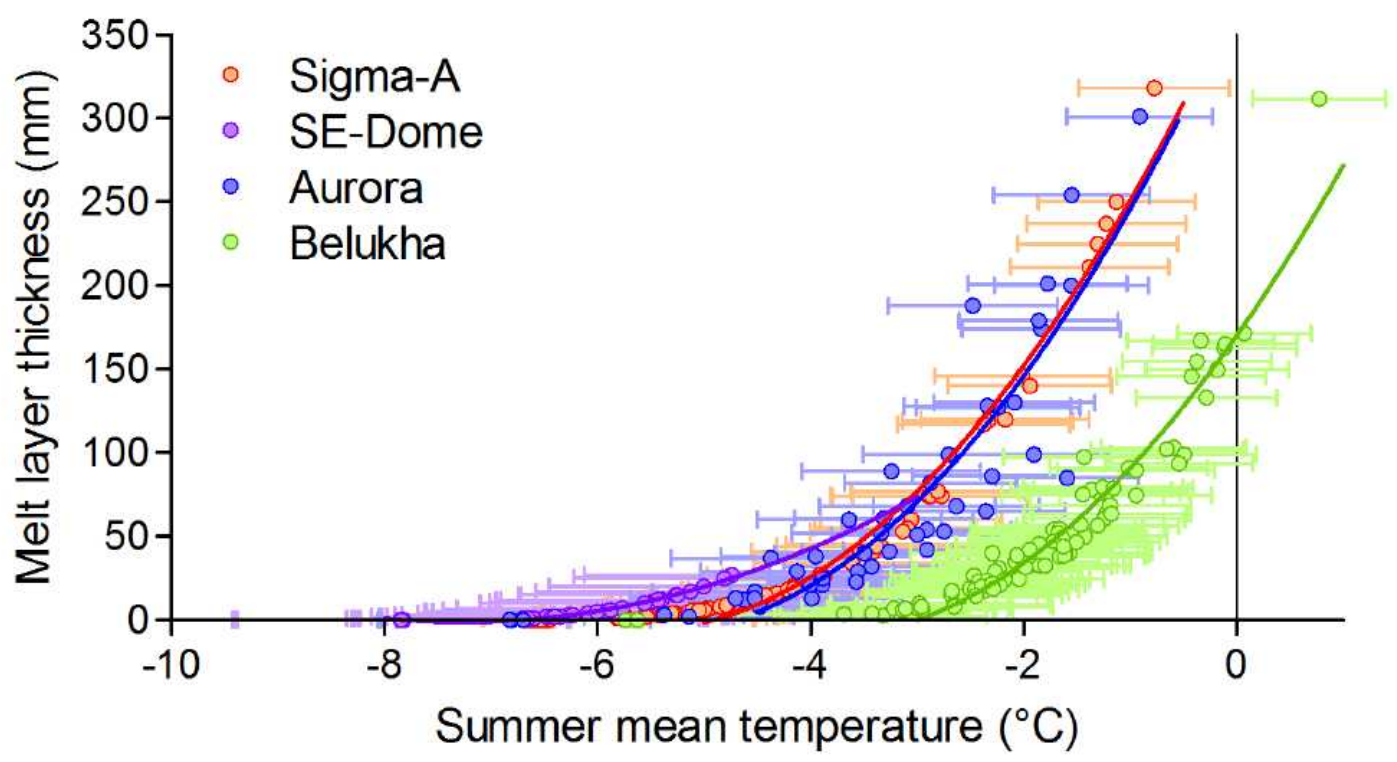

Interactive comment

Fig. 1. Modified figure of Fig. 8 